\title{
Characterization of novel germline c-kit gene mutation, KIT-Tyr553Cys, observed in a family with multiple gastrointestinal stromal tumors
}

\author{
Mayumi Nakai ${ }^{1}$, Yuka Hashikura ${ }^{1}$, Mizuka Ohkouchi ${ }^{1}$, Masahiro Yamamura ${ }^{2}$, Takashi Akiyama ${ }^{3}$, Kazuhiro Shiba ${ }^{1}$, \\ Noriko Kajimoto' ${ }^{1}$ Yoshitane Tsukamoto ${ }^{1}$, Hiroyuki Hao ${ }^{1}$, Koji Isozaki ${ }^{1}$, Toshihiro Hirai ${ }^{4}$ and Seiichi Hirota ${ }^{1}$
}

We found a novel type germline mutation at exon 11 of the c-kit gene, which results in a substitution of Tyr to Cys at codon 553 of the c-kit gene product (KIT-Tyr553Cys), in a 68-year-old female patient with multiple gastrointestinal stromal tumors (GISTs). In the present study, we carried out mutational analysis in her family members to determine the carriers and characterized the mutation by introducing the corresponding mutation (murine KIT-Tyr552Cys) into expression vector possessing murine c-kit cDNA. Mutational analysis of peripheral blood leukocytes of her family members revealed that a 44-year-old son had the same mutation, but at present he had neither apparent symptoms nor images of multiple GISTs. By transfection with the expression vector possessing the murine mutant c-kit cDNA, interleukin-3-dependent $\mathrm{Ba} / \mathrm{F} 3$ murine lymphoid cells started growing autonomously without any growth factors, indicating that the mutation was considered to be of gain-of-function. Imatinib, a small molecule of tyrosine kinase inhibitor, effectively inhibited autophosphorylation of KIT-Tyr552Cys. Nilotinib, another small molecule of the KIT inhibitor, also effectively inhibited autophosphorylation of KIT-Tyr552Cys. In fact, proliferation of Ba/F3 cells expressing KIT-Tyr552Cys was effectively inhibited by both imatinib and nilotinib. These findings indicate that the novel type human KIT-Tyr553Cys mutation is the cause of the present familial and multiple GISTs, and that both imatinib and nilotinib might effectively inhibit the growth of GISTs developing in the patients of this family.

Laboratory Investigation (2012) 92, 451-457; doi:10.1038/labinvest.2011.165; published online 14 November 2011

KEYWORDS: exon 11; gastrointestinal stromal tumor; germline mutation; imatinib; juxtamembrane domain; nilotinib; tyrosine kinase inhibitor

Gastrointestinal stromal tumors (GISTs) are the most common mesenchymal tumors of the human gut. Most GISTs are positive for $\mathrm{KIT}^{1}$ a receptor tyrosine kinase (TK), which is encoded by the c-kit proto-oncogene. ${ }^{2,3}$ Interstitial cells of Cajal (ICCs) in the gastrointestinal wall, which are considered to regulate the gastrointestinal motility through their spontaneous impulse generation, ${ }^{4}$ are also positive for KIT. $^{5-7}$ Some other markers of GISTs such as CD34, ${ }^{1}$ embryonic form of smooth muscle myosin heavy chain, ${ }^{8}$ nestin, ${ }^{9}$ DOG $1,{ }^{10}$ and ETV $1{ }^{11}$ have been demonstrated to be common markers of ICCs. Therefore, GISTs are now considered to originate from ICCs or their precursor.

KIT consists of an extracellular domain with five immunoglobulin-like repeats, a transmembrane domain, a juxta- membrane domain, and TK I and II domains split by the kinase insert. $^{2,3}$ Stem cell factor (SCF) is a ligand for KIT, ${ }^{12}$ and the SCF-KIT system has a crucial role in development of melanocytes, erythrocytes, germ cells, mast cells and ICCs. ${ }^{5-7,13,14}$ Somatic gain-of-function mutations of the c-kit gene are observed in some types of human tumors such as GISTs, ${ }^{1,15}$ mast cell tumors, ${ }^{16,17}$ germ cell tumors, ${ }^{18}$ and malignant melanomas. ${ }^{19,20}$ Most of the mutations are detected in four different exons, ie, exon 9, exon 11, exon 13, and exon 17. ${ }^{1,15-20}$ These mutations essentially result in the constitutive activation of KIT. In sporadic GISTs, the most frequent mutations are located at exon 11. ${ }^{1,15}$ In rarer cases, the mutations are found at exon 9 encoding the extracellular domain, $^{15,21,22}$ at exon 13 encoding the TK I domain, ${ }^{15,21,23}$

\footnotetext{
'Department of Surgical Pathology, Hyogo College of Medicine, Nishinomiya, Japan; ${ }^{2}$ Department of Clinical Oncology, Kawasaki Medical School, Kurashiki, Japan; ${ }^{3}$ Department of Pathology, Kawasaki Medical School, Kurashiki, Japan and ${ }^{4}$ Division of Gastroenterology, Department of Surgery, Kawasaki Medical School, Kurashiki, Japan

Correspondence: Dr S Hirota, MD, PhD, Department of Surgical Pathology, Hyogo College of Medicine, Mukogawa-cho 1-1, Nishinomiya, Hyogo 663-8501, Japan. E-mail: hiros@hyo-med.ac.jp

Received 8 September 2011; revised 7 October 2011; accepted 10 October 2011
} 
or at exon 17 encoding the TK II domain. ${ }^{15,21,23}$ In melanomas, most of the mutations are also present at exon $11 .{ }^{19,20}$ However, most of them are located at exon 17 in both human mast cell tumors and germ cell tumors. ${ }^{16-18}$

Imatinib, one of the TK inhibitors, potently inhibits KIT activity and is now used for the treatment of advanced GISTs. ${ }^{24}$ Imatinib is well known to show remarkable inhibitory effect to most exon $11 \mathrm{c}-k i t$ gene mutations but not to most exon 17 c-kit gene mutations. ${ }^{25}$ In fact, it has remarkable effect to most GISTs with exon $11 \mathrm{c}$-kit gene mutations. ${ }^{26}$ But secondary resistance to imatinib often develops during long-term use. ${ }^{27}$ Most common mechanism of the secondary resistance is considered to be addition of second mutation at exon 13 or exon 17 of the c-kit gene. ${ }^{28}$ Sunitinib, another TK inhibitor, is now used for imatinib-resistant GISTs, but the effect is limited. ${ }^{29}$ Therefore, many other reagents including another TK inhibitor, nilotinib, are under development for GIST treatment.

We published the first case of familial and multiple GISTs with germline mutation at exon 11 of the c-kit gene in $1998 .^{30}$ To our knowledge, $\sim 20$ families with germline c-kit gene mutations and multiple GISTs have been reported so far. $^{31-49}$ Thirteen families including the first case have the

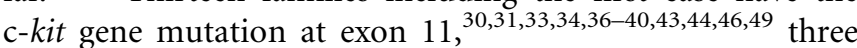
families at exon $13,,^{32,45,48}$ three families at exon $17^{35,42,47}$ and one family at exon $8 .^{41}$ In addition to multiple GISTs, patients of these families have hyperplasia of ICCs in the gut wall. Recently, we found a 68-year-old Japanese woman who had an operation for multiple mesenchymal tumors of the stomach, ileum and the cecum. These tumors were KITpositive GISTs, and she also had hyperplasia of ICCs in the stomach and small intestine. Mutational analysis of her GIST tissues and peripheral blood leukocytes revealed that she had a novel type of germline c-kit gene mutation, KIT-Tyr553Cys, at exon 11. In the present study, we carried out mutational analysis in the family members to determine the carriers, and characterized the novel type germline mutation including inhibitory effect of TK inhibitors such as imatinib and nilotinib.

\section{MATERIALS AND METHODS Analysis of Germline c-kit Gene Mutation Using Genomic DNA}

Genomic DNA was extracted from peripheral blood using GenTLE Kit (Takara, Otsu, Japan), according to the manufacturer's instructions. DNA fragment of exon 11 of the c-kit gene was amplified by PCR using forward primer ( $5^{\prime}$-GAGTG CTCTAATGACTGAGA- $3^{\prime}$ ) and reverse primer ( $5^{\prime}$-AAAGGT GACATGGAAAGCCC- $3^{\prime}$ ), and was sequenced directly by using the same primers. Exons 9, 13 and 17 of genomic c-kit DNA were also amplified by PCR as described previously. ${ }^{50}$ Present analysis was performed after taking informed consent from the family members, under the approval of the authors' institutional ethical committees, and according to fundamental principles of research on the human genome recommended by the Japanese Ministry of Education, Culture, Sports, Science and Technology.

\section{Generation of $\mathrm{Ba} / \mathrm{F} 3$ Cells Expressing Murine KIT-Tyr552Cys}

Murine c-kit gene mutation (murine KIT-Tyr552Cys) corresponding to human c-kit gene mutation (human KITTyr553Cys) was introduced into expression vector possessing murine c-kit cDNA using site-directed mutagenesis as described previously. ${ }^{1}$ The expression vector was transfected into interleukin-3 (IL-3)-dependent Ba/F3 murine lymphoid cell line, and selection of the transfectant was done as described previously. ${ }^{1}$ The stable transfectant was cloned with the method of limiting dilution.

\section{Proliferation Profile of $\mathrm{Ba} / \mathrm{F3}$ Cells Expressing Murine KIT-Tyr552Cys}

To evaluate the proliferation profile of $\mathrm{Ba} / \mathrm{F} 3$ cells expressing murine KIT-Tyr552Cys in the presence or absence of factors, MTS (3-(4,5-dimethylthiazol-2-yl)-5-(3-carboxymethoxyphenyl)-2-(4-sulfophenyl)-2H-tetrazolium inner salt) colorimetric assay was performed using CellTiter 96 AQueous One Solution Cell Proliferation Assay (G3580, Promega Corporation, Madison, WI, USA), according to the manufacturer's instruction. Briefly, cells were plated in a 96-well plate at a concentration of $1.5 \times 10^{4}$ cells/well and cultured with various concentrations of recombinant mouse (rm) IL-3 $(0,0.01,0.1,1$ and $10 \mathrm{ng} / \mathrm{ml})$ or $\operatorname{rmSCF}(0,1,10,100$, and $1000 \mathrm{ng} / \mathrm{ml}$ ) for $48 \mathrm{~h}$. Then cells were further cultured for $2 \mathrm{~h}$ in the presence of MTS. The optical density was measured with a test wavelength of $490 \mathrm{~nm}$ and a reference wavelength of $650 \mathrm{~nm} . \mathrm{Ba} / \mathrm{F} 3$ cells expressing another murine exon 11 c-kit gene mutation, KIT-del-(Val558\&Val559), corresponding to human exon $11 \mathrm{c}$-kit gene mutation, KITdel-(Val559\&Val560), which are known to show factor-independent growth, ${ }^{1}$ and those expressing murine wild-type c-kit gene, which are known to show factor-dependent growth, ${ }^{1}$ were used as comparisons.

\section{Effect of KIT Inhibitors on Autophosphorylation of Murine KIT-Tyr552Cys}

To evaluate the effect of imatinib (a generous gift from Novartis, Basel, Switzerland) and nilotinib (a generous gift from Novartis) on autophosphorylation of murine mutant KIT-Tyr552Cys, $3 \times 10^{6} \mathrm{Ba} / \mathrm{F} 3$ cells expressing the mutation were cultured at various concentrations of imatinib $(0,0.001$, $0.01,0.1,1$ and $10 \mu \mathrm{M})$ or nilotinib $(0,0.001,0.01,0.1,1$ and $10 \mu \mathrm{M})$ for $90 \mathrm{~min}$. Then, cells were collected and lysed as described previously. ${ }^{1}$ Phosphorylation of KIT was detected by rabbit polyclonal anti-phospho-c-KIT antibody (pTyr823, Affinity BioReagents, Golden, CO, USA). Reprobing was done with rabbit polyclonal anti-KIT antibody (A4502, Dako, Glostrup, Denmark). Ba/F3 cells expressing another murine exon 11 c-kit gene mutation, KIT-del-(Val558\&Val559), corresponding to human c-kit gene mutation, 
KIT-del-(Val559\&Val560), which is known to be sensitive to imatinib, ${ }^{25}$ were used as a comparison. $\mathrm{Ba} / \mathrm{F} 3$ cells expressing murine c-kit gene mutation, KIT-Val653Ala, corresponding to human c-kit gene mutation, KIT-Val654Ala, which is known to be resistant to imatinib, ${ }^{51}$ were also used as another comparison.

\section{Effect of KIT Inhibitors on Proliferation of Ba/F3 Cells Expressing Murine KIT-Tyr552Cys}

To evaluate the effect of imatinib and nilotinib on proliferation of $\mathrm{Ba} / \mathrm{F} 3$ cells expressing murine mutant KITTyr552Cys, MTS colorimetric assay was performed using CellTiter 96 AQueous One Solution Cell Proliferation Assay (Promega). Briefly, cells were plated in a 96-well plate at a concentration of $1.5 \times 10^{4}$ cells/well and cultured with various concentrations of imatinib $(0,0.001,0.01,0.1,1$ and $10 \mu \mathrm{M})$ or nilotinib $(0,0.001,0.01,0.1,1$ and $10 \mu \mathrm{M})$ for $48 \mathrm{~h}$. Then the cells were further cultured for $2 \mathrm{~h}$ in the presence of MTS. The optical density was measured with a test wavelength of $490 \mathrm{~nm}$ and a reference wavelength of $650 \mathrm{~nm} . \mathrm{Ba} / \mathrm{F} 3$ cells expressing another murine c-kit gene mutation, KIT-6 codons-(549-554) to Ile, corresponding to human c-kit gene mutation, KIT-6 codons-(550-555) to Ile, were used as a control. Ba/F3 cells expressing murine c-kit gene mutation, KIT-Val653Ala, corresponding to human c-kit gene mutation, KIT-Val654Ala, were also used as another control.

\section{RESULTS}

\section{Analysis of Germline c-kit Gene Mutation in Family Members}

We examined whether family members of the proband (case 6 in Figure 1) had the germline mutation, KIT-Tyr553Cys, by direct sequencing of genomic DNA from peripheral blood leukocytes. A son (44-year-old, case 7 in Figure 1) of the proband had the same germline mutation of the c-kit gene at exon 11 (data not shown). On the other hand, a brother (80year-old, case 3 in Figure 1), a sister (76-year-old, case 4 in Figure 1) and a daughter (40-year-old, case 8 in Figure 1) of the proband did not show any mutations at exons 9, 11, 13 and 17 (data not shown). A sister (72-year-old, case 5 in Figure 1) of the proband did not allow us to examine the mutation. As the father (case 1 in Figure 1) and mother (case 2 in Figure 1) of the proband died from senility at age of 88 and 90 years, respectively, we could not analyze genomic DNA of them. There was a possibility that the son's two children (a 13-year-old son and a 10-year-old daughter, case 9 and case 10 in Figure 1, respectively) had the germline mutation, but we could not carry out the mutational analysis in them because of their young age. All family members examined including the proband did not report dysphagia, hyperpigmentation and symptoms suggesting mast cell tumor, germ cell tumor or neurofibromatosis type 1 .

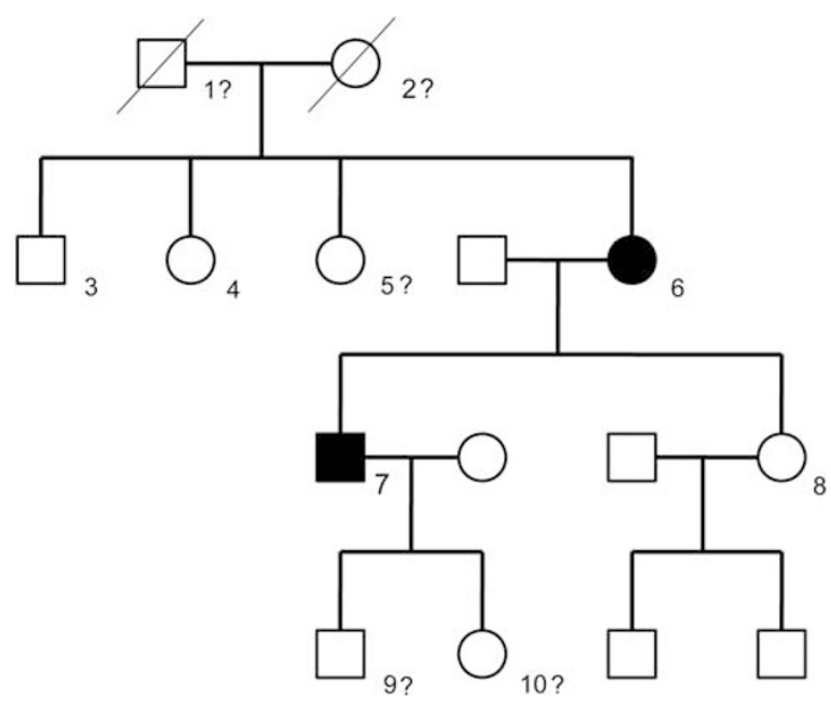

Figure 1 Pedigree of the family. Case 6 is the proband. Filled symbols show the family members with germline c-kit gene mutation. Squares and circles indicate males and females, respectively. Symbols with '/' mean dead cases at the time of investigation. Persons who have not taken mutational test because of refusal (cases 5,9 and 10) or death (cases 1 and 2) are indicated by '?'.

\section{Proliferation Profile of $\mathrm{Ba} / \mathrm{F} 3$ Cells Expressing Murine KIT-Tyr552Cys}

Murine c-kit gene mutation (murine KIT-Tyr552Cys) corresponding to human c-kit gene mutation (human KITTyr553Cys) was introduced into expression vector possessing murine c-kit cDNA, and it was stably transfected into the IL-3-dependent $\mathrm{Ba} / \mathrm{F} 3$ cells. MTS colorimetric assay was carried out to clarify the proliferation profile of the transfectant in the presence or absence of rmIL-3 and rmSCF. Transfectant expressing murine wild-type KIT and that expressing another exon 11 murine mutant KIT, which is proved to be factor-independent cells, ${ }^{1}$ were used as controls. $\mathrm{Ba} / \mathrm{F} 3$ cells with wild-type KIT responded to both rmIL-3 and rmSCF (Figures 2a and b). On the other hand, Ba/F3 cells with murine mutant KIT-Tyr552Cys grew autonomously without rmIL-3 and rmSCF as observed in those with another exon 11 mutant KIT (Figures $2 \mathrm{a}$ and $\mathrm{b}$ ).

\section{Effect of KIT Inhibitors on Autophosphorylation of Murine KIT-Tyr552Cys}

$\mathrm{Ba} / \mathrm{F} 3$ cells expressing murine mutant KIT-Tyr552Cys were treated with imatinib or nilotinib, and autophosphorylation of the mutant KIT was examined. Transfectant with another exon 11 mutant KIT, which is known to be sensitive to imatinib, ${ }^{25}$ and that with exon 13 mutant KIT, which is known to be resistant to imatinib, ${ }^{51}$ were also treated with the reagents as controls. Autophosphorylation of mutant KIT-Tyr552Cys was inhibited by imatinib at the concentration of $0.1 \mu \mathrm{M}$ as well as that of another exon 11 mutant KIT (Figure 3). In contrast, autophosphorylation of murine exon 13 mutant KIT was not inhibited at the concentration of 
a

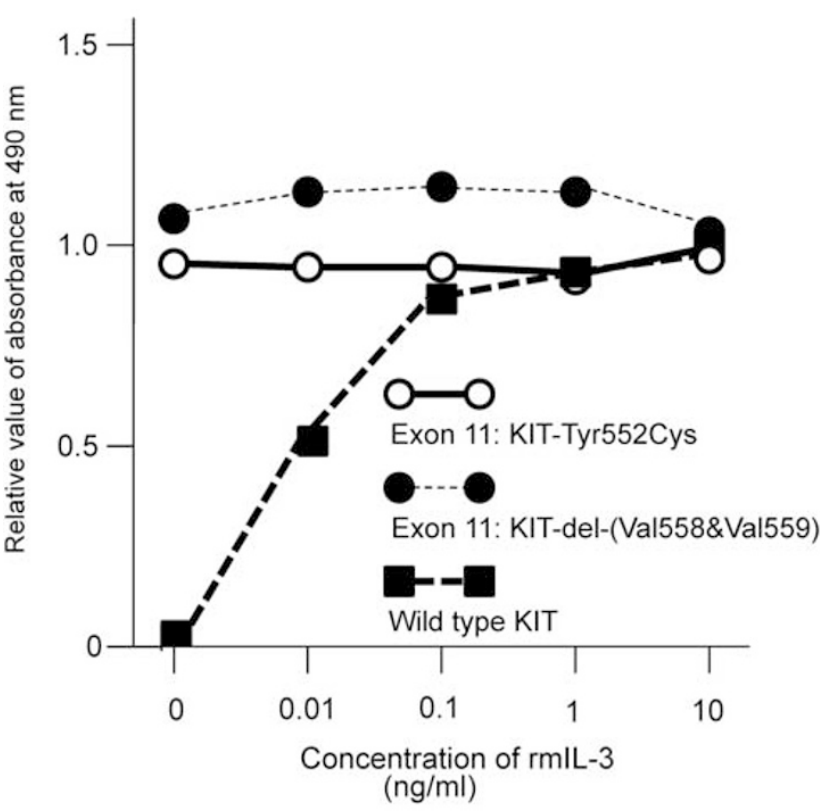

b

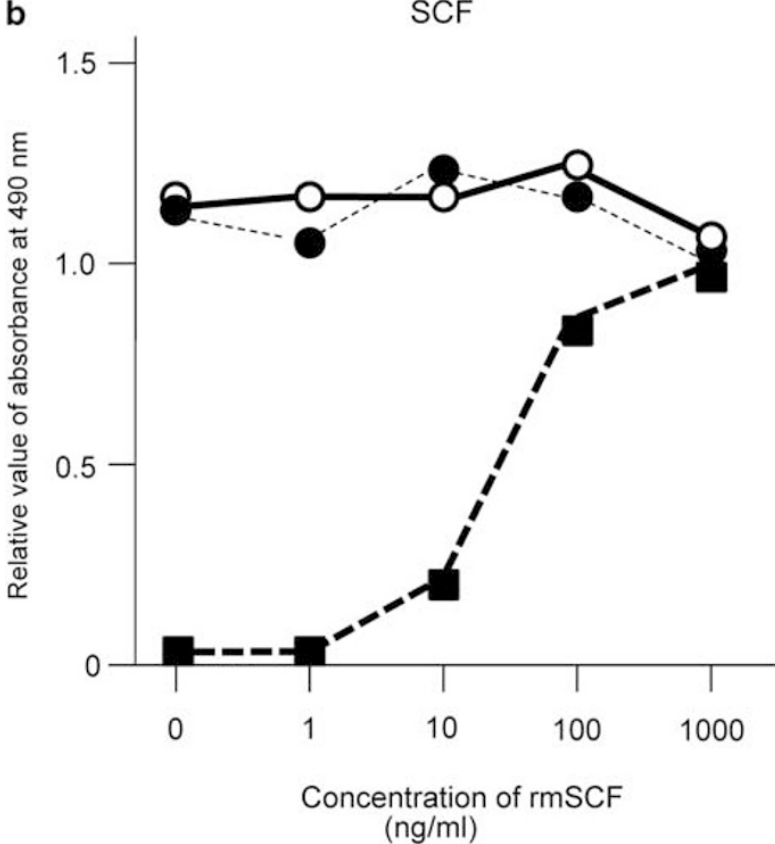

Figure 2 Autonomous proliferation of $\mathrm{Ba} / \mathrm{F} 3$ cells with murine KITTyr552Cys. Ba/F3 cells with mouse wild-type c-kit CDNA and those with murine KIT-del-(Val558\&Val559) were used as controls. (a) MTS (3-(4,5dimethylthiazol-2-yl)-5-(3-carboxymethoxyphenyl)-2-(4-sulfophenyl)-2Htetrazolium inner salt) colorimetric assay in the presence or absence of recombinant mouse (rm) interleukin-3 (IL-3). (b) MTS colorimetric assay in the presence or absence of $\mathrm{rm}$ stem cell factor (SCF). Ba/F3 cells with wild-type KIT responded to both rmIL-3 and rmSCF, but those with KIT-Tyr552Cys and KIT-del-(Val558\&Val559) grew autonomously without rmIL-3 and rmSCF. Ba/F3 cells with mutant KIT-Tyr552Cys $(O), \mathrm{Ba} / \mathrm{F} 3$ cells with mutant KIT-del-(Val558\&Val559) (@), and Ba/F3 cells with wild KIT ( $(\mathbf{0})$. Data are expressed as the mean of six wells. The values of vertical axis are expressed as the relative ones when the mean value of the optical density on $10 \mathrm{ng} / \mathrm{ml}$ is regarded as 1.0 in case of $\mathrm{rmlL} 3$ and that on $1000 \mathrm{ng} / \mathrm{ml}$ is regarded as 1.0 in case of $\mathrm{rmSCF}$.
$0.1 \mu \mathrm{M}$ and was completely inhibited just at the concentration of $10 \mu \mathrm{M}$ (Figure 3). When nilotinib was used instead of imatinib, autophosphorylation of mutant KIT-Tyr552Cys was similarly inhibited at the concentration of $0.1 \mu \mathrm{M}$ (Figure 4). Autophosphorylation of another exon 11 mutant KIT was also inhibited at the concentration of $0.1 \mu \mathrm{M}$, and that of the murine exon 13 mutant KIT was completely inhibited just at the concentration of $10 \mu \mathrm{M}$ (Figure 4).

\section{Effect of KIT Inhibitors on Proliferation of Ba/F3 Cells Expressing Murine KIT-Tyr552Cys}

MTS assay was carried out to assess the inhibitory effect of imatinib and nilotinib on the proliferation of transfectant with mutant KIT-Tyr552Cys. Ba/F3 cells expressing another exon 11 mutant KIT and those expressing imatinib-resistant exon 13 mutant KIT were also examined as controls. Imatinib completely inhibited autonomous proliferation of both $\mathrm{Ba} / \mathrm{F} 3$ cells expressing mutant KIT-Tyr552Cys and those expressing another exon 11 mutant KIT at the concentration of $0.1 \mu \mathrm{M}$.

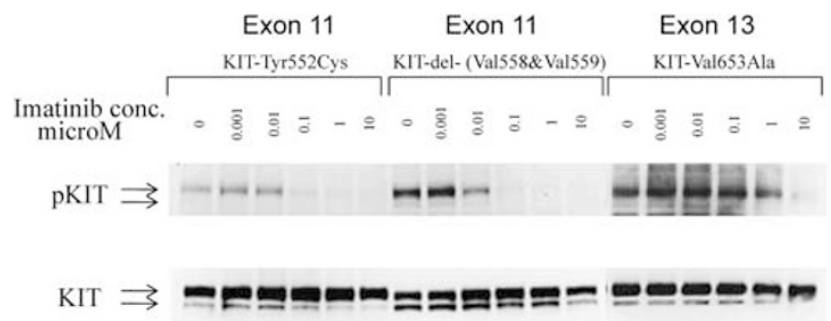

Figure 3 Effect of imatinib on autophosphorylation of murine KITTyr552Cys. Autophosphorylation of mutant KIT was examined after $90 \mathrm{~min}$ incubation of $\mathrm{Ba} / \mathrm{F} 3$ cells expressing the mutant $\mathrm{KIT}$ at concentrations of 0 , $0.001,0.01,0.1,1$ and $10 \mu \mathrm{M}$ of imatinib. Imatinib-sensitive murine KIT-del(Val558\&Val559) and imatinib-resistant murine KIT-Val653Ala were also examined as controls. Autophosphorylation of KIT-Tyr552Cys was almost completely inhibited at a concentration of $0.1 \mu \mathrm{M}$ as well as that of KIT-del(Val558\&Val559). In contrast, autophosphorylation of KIT-Val653Ala was not even at $1 \mu \mathrm{M}$.

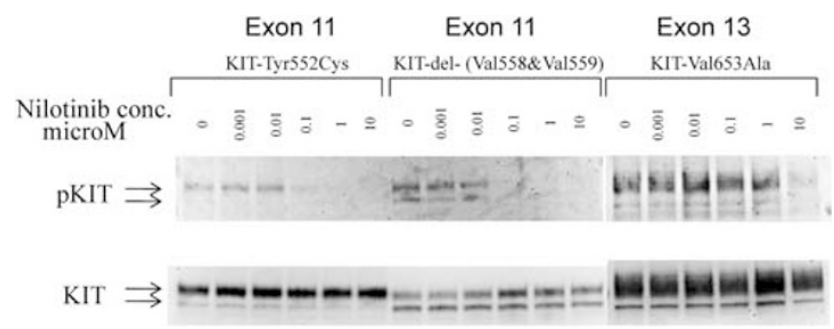

Figure 4 Effect of nilotinib on autophosphorylation of murine KITTyr552Cys. Autophosphorylation of mutant KIT was examined after $90 \mathrm{~min}$ incubation of $\mathrm{Ba} / \mathrm{F} 3$ cells expressing the mutant $\mathrm{KIT}$ at concentrations of 0 , $0.001,0.01,0.1,1$ and $10 \mu \mathrm{M}$ of nilotinib. Imatinib-sensitive murine KIT-del(Val558\&Val559) and imatinib-resistant murine KIT-Val653Ala were also examined as controls. Similarly in imatinib, autophosphorylation of KITTyr552Cys and KIT-del-(Val558\&Val559) was almost completely inhibited at a concentration of $0.1 \mu \mathrm{M}$; on the other hand, that of KIT-Val653Ala was just at $10 \mu \mathrm{M}$. 
However, autonomous proliferation of $\mathrm{Ba} / \mathrm{F} 3$ cells expressing exon 13 mutant KIT was inhibited just at the concentration of $10 \mu \mathrm{M}$ (Figure 5). Nilotinib also completely inhibited autonomous proliferation of $\mathrm{BaF} / 3$ cells expressing mutant KIT-Tyr552Cys at the concentration of $0.1 \mu \mathrm{M}$. Autonomous proliferation of $\mathrm{Ba} / \mathrm{F} 3$ cells with another exon 11 mutant KIT was also inhibited at $0.1 \mu \mathrm{M}$, but that with exon 13 mutant KIT was just at the concentration of $10 \mu \mathrm{M}$ (Figure 6).

\section{DISCUSSION}

So far, $\sim 20$ families with germline c-kit gene mutations and multiple GISTs have been reported, ${ }^{30-49}$ and the mutations were detected at exon 11 in 12 families. ${ }^{30,31,33,34,36-40,43,44,46,49}$ KIT-Val559Ala mutation is the most frequent type, which has been detected in five families. ${ }^{33,34,38,39,49}$ Recently, we found a germline mutation at exon 11, KIT-Tyr553Cys, in a 68-yearold woman with multiple GISTs. To our knowledge, this type of mutation has not been reported yet. In the present study, we carried out analysis of the novel germline mutation in the

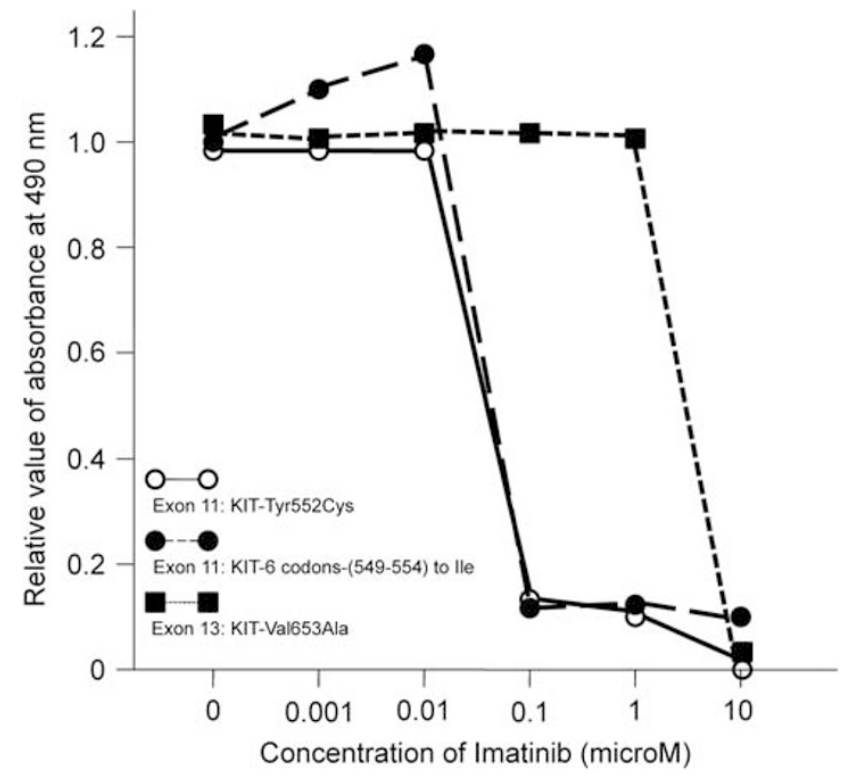

Figure 5 Effect of imatinib on in vitro cell proliferation of $\mathrm{Ba} / \mathrm{F} 3$ cells with murine KIT-Tyr552Cys. Cells were incubated for $48 \mathrm{~h}$ at concentrations of 0 , $0.001,0.01,0.1,1$ and $10 \mu \mathrm{M}$ of imatinib, and MTS (3-(4,5-dimethylthiazol-2yl)-5-(3-carboxymethoxyphenyl)-2-(4-sulfophenyl)-2H-tetrazolium inner salt) colorimetric assay was carried out. Ba/F3 cells expressing KIT-Tyr552Cys, those expressing imatinib-sensitive murine KIT-6 codons-(549-554) to lle, and those expressing imatinib-resistant murine KIT-Val653Ala were used. Proliferation of both BaF3 cells expressing KIT-Tyr552Cys and those expressing KIT-6 codons-(549-554) to lle was completely inhibited at the concentration of $0.1 \mu \mathrm{M}$ of imatinib. On the other hand, proliferation of $\mathrm{Ba} / \mathrm{F} 3$ cells expressing KIT-Val653Ala was inhibited just at the concentration of $10 \mu \mathrm{M}$. Ba/F3 cells with murine KIT-Tyr552Cys $(\mathrm{O}), \mathrm{Ba} / \mathrm{F} 3$ cells with murine KIT-6 codons-(549-554) to lle $(\bullet)$ and $\mathrm{Ba} / \mathrm{F3}$ cells with murine KIT-Val653Ala ( $\mathbf{\square})$. Data are expressed as the mean of six wells. The values are expressed as the relative ones when each mean value of the optical density on $0 \mu \mathrm{M}$ of imatinib is regarded as 1.0. family members to determine the carriers, and characterized the mutation including inhibitory effect of TK inhibitors such as imatinib and nilotinib.

We found that a 44-year-old son of the proband had the germline mutation, but at present he did not show apparent symptoms and images of multiple GISTs. The penetration rate of multiple GIST development in persons with various types of germline c-kit gene mutations appears to be nearly $100 \%$. As multiple GISTs and symptoms associated with the tumors often develop in over 50-year-old persons, the son must be closely followed hereafter for development of multiple GISTs.

Most of the somatic gain-of-function mutations of the c-kit gene are detected at exon 9, exon 11, exon 13 or exon 17 in GISTs, mast cell tumors, seminomas or melanomas. ${ }^{1,15-23}$ Similarly, germline loss-of-function mutations of the c-kit gene in various $\mathrm{W}$ mutant mice are often observed at exon 11, exon 13 or exon $17 .^{52}$ Mutation of murine c-kit gene at codon 582, KIT-Gln582Lys, corresponding to human KITGln583Lys is a cause of $\mathrm{W}^{37}$ loss-of-function mutant mice. ${ }^{52}$

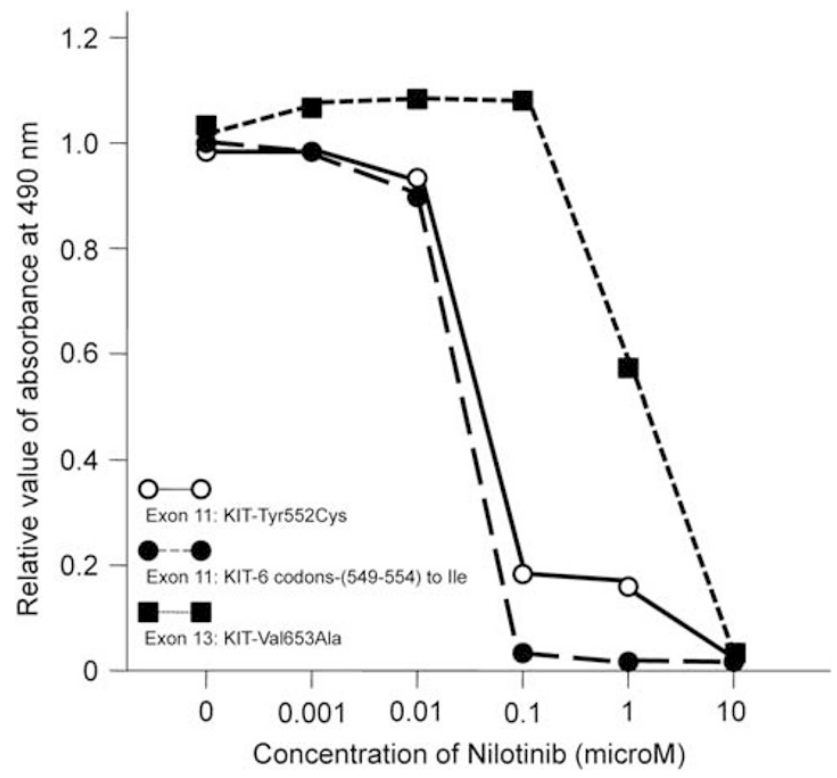

Figure 6 Effect of nilotinib on in vitro cell proliferation of $\mathrm{Ba} / \mathrm{F} 3$ cells with murine KIT-Tyr552Cys. Cells were incubated for $48 \mathrm{~h}$ at concentrations of 0 , $0.001,0.01,0.1,1$ and $10 \mu \mathrm{M}$ of nilotinib, and MTS (3-(4,5-dimethylthiazol-2yl)-5-(3-carboxymethoxyphenyl)-2-(4-sulfophenyl)-2H-tetrazolium inner salt) colorimetric assay was carried out. Similarly in imatinib, $\mathrm{Ba} / \mathrm{F} 3$ cells expressing KIT-Tyr552Cys, those expressing imatinib-sensitive murine KIT-6 codons-(549-554) to lle and those expressing imatinib-resistant murine KIT-Val653Ala were used. Nilotinib completely inhibited proliferation of both BaF3 cells expressing KIT-Tyr552Cys and those expressing KIT-6 codons-(549-554) to lle at the concentration of $0.1 \mu \mathrm{M}$. In contrast, proliferation of $\mathrm{Ba} / \mathrm{F} 3$ cells expressing $\mathrm{KIT}$-Val653Ala was inhibited just at the concentration of $10 \mu \mathrm{M}$. Ba/F3 cells with murine KIT-Tyr552Cys $(O)$, $\mathrm{Ba} / \mathrm{F} 3$ cells with murine KIT-6 codons-(549-554) to lle $(\bullet)$ and Ba/F3 cells with murine KIT-Val653Ala ( $\mathbf{\square})$. Data are expressed as the mean of six wells. The values are expressed as relative ones when each mean value of the optical density on $0 \mu \mathrm{M}$ of nilotinib is regarded as 1.0. 
Therefore, it does not always mean that the c-kit gene mutations at exon 11 are of gain-of-function. In the present study, we clarified that transfection of the murine c-kit gene mutation, KIT-Tyr552Cys, corresponding to human c-kit gene mutation, KIT-Tyr553Cys, converted IL-3-dependent $\mathrm{Ba} / \mathrm{F} 3$ cells to factor-independent cells. This suggests that the c-kit gene mutation, KIT-Tyr553Cys, is of gain-of-function and the cause of familial and multiple GISTs in the present case.

The proband showed ICC hyperplasia, which is nearly always observed in patients with familial and multiple GISTs. Although hyperpigmentation is often seen and mast cell tumor is sometimes seen in previously reported patients with exon 11 germline c-kit gene mutation, ${ }^{30,33,34,36-38,44,48}$ the present patient and her son, a possible carrier, did not show those phenotypes. Dysphagia is also a symptom that is often seen in exon 17 germline c-kit gene mutation, ${ }^{35,42}$ but is rarely seen in exon 11 germline ones. ${ }^{36}$ In fact, the present patient and her son also did not have the symptom. Those phenotypes and symptoms might not be associated with this type of germline c-kit gene mutation.

As described above, various types of exon 11 germline c-kit gene mutations have been reported, ${ }^{30,31,33,34,36-40,43,44,46,49}$ but KIT-Tyr553Cys mutation has not been reported yet. Even in somatic c-kit gene mutation in sporadic GISTs, substitution of amino acid at codon 553 appears to be very rare. We experienced only one case of sporadic GIST with substitution at codon 553 in over 300 sporadic GISTs examined. Moreover, the mutation is not Tyr553Cys but Tyr553Asn (unpublished data). In malignant melanoma, a case with Tyr553Asn mutation has been reported. ${ }^{20}$

Most of the exon 11 mutations of the c-kit gene are imatinib sensitive. ${ }^{53}$ However, we reported that certain type of the exon 11 mutation observed in mast cell tumor, Val559Ile, is resistant to imatinib. ${ }^{54}$ In the present study, we clarified whether murine KIT-Tyr552Cys corresponding to human KIT-Tyr553Cys is sensitive to imatinib and nilotinib. Phosphorylation of the KIT-Tyr552Cys was nearly completely inhibited at the concentration of $0.1 \mu \mathrm{M}$ of both imatinib and nilotinib, as well as that of another exon 11 mutant KIT that is proved to be sensitive to imatinib. In fact, proliferation of the cells expressing KIT-Tyr552Cys was nearly completely inhibited at the concentration of $0.1 \mu \mathrm{M}$ of both imatinib and nilotinib, as well as that expressing another exon 11 mutant KIT. The novel type of the human KIT-Tyr553Cys mutation is considered to be sensitive to both imatinib and nilotinib.

In summary, we found a carrier with the novel type of the c-kit gene mutation in the family, and showed that the mutation is imatinib and nilotinib sensitive. When the patients of the family need the treatment by imatinib or nilotinib, these drugs might be effective on control of GISTs.

\section{DISCLOSURE/CONFLICT OF INTEREST}

Dr Hirota has received donations for research support from Novartis. All authors except Dr Hirota do not have any conflict of interest declared.
1. Hirota S, Isozaki K, Moriyama Y, et al. Gain-of-function mutations of c-kit in human gastrointestinal stromal tumors. Science 1998;279: 577-580.

2. Yarden Y, Kuang WJ, Yang-Feng T, et al. Human proto-oncogene c-kit: a new cell surface receptor tyrosine kinase for an unidentified ligand. EMBO J 1987;6:3341-3351.

3. Qiu FH, Ray HP, Brown Y, et al. Primary structure of c-kit: relationship with the CSF-1/PDGF receptor kinase family-oncogenic activation of $\mathrm{v}$-kit involves deletion of extracellular domain and $\mathrm{C}$ terminus. EMBO J 1988;7:1003-1011.

4. Thomsen L, Robinson TL, Lee JCF, et al. Interstitial cells of Cajal generate a rhythmic pacemaker current. Nat Med 1998;4:848-851.

5. Maeda H, Yamagata A, Nishikawa S, et al. Requirement of c-kit for development of intestinal pacemaker system. Development 1992; 116:369-375.

6. Huizinga JD, Thuneberg $L$, Kluppel $M$, et al. W/kit gene required for interstitial cells of Cajal and for intestinal pacemaker activity. Nature 1995;373:347-349.

7. Isozaki K, Hirota S, Nakama A, et al. Disturbed intestinal movement, bile reflux to the stomach, and deficiency of c-kit-expressing cells in Ws/Ws mutant rats. Gastroenterology 1995;109:456-464.

8. Sakurai S, Fukasawa T, Chong JM, et al. Embryonic form of smooth muscle myosin heavy chain (SMemb/MHC-B) in gastrointestinal stromal tumor and interstitial cells of Cajal. Am J Pathol 1999;154: 23-28.

9. Tsujimura T, Makiishi-Shimobayashi C, Lundkvist J, et al. Expression of the intermediate filament nestin in gastrointestinal stromal tumors and interstitial cells of Cajal. Am J Pathol 2001;158:817-823.

10. Gomez-Pinilla PJ, Gibbons SJ, Bardsley MR, et al. Ano1 is a selective marker of interstitial cells of Cajal in the human and mouse gastrointestinal tract. Am J Physiol Gastrointest Liver Physiol 2009;296:G1370-G1381.

11. Chi $P$, Chen $Y$, Zhang $L$, et al. ETV1 is a lineage survival factor that cooperates with KIT in gastrointestinal stromal tumours. Nature 2010;467:849-853.

12. Williams DE, Eisenman J, Baird A, et al. Identification of a ligand for the c-kit proto-oncogene. Cell 1990;63:167-174.

13. Russell ES. Hereditary anemias of the mouse: a review for geneticists. Adv Genet 1979;20:357-459.

14. Kitamura $Y$, Go S. Decreased production of mast cells in $S / / S I^{d}$ anemic mice. Blood 1979;53:492-497.

15. Lux ML, Rubin BP, Biase $\mathrm{TL}$, et al. KIT extracellular and kinase domain mutations in gastrointestinal stromal tumors. Am J Pathol 2000;156: 791-795.

16. Nagata $\mathrm{H}$, Worobec $\mathrm{AS}$, Oh $\mathrm{CK}$, et al. Identification of a point mutation in the catalytic domain of the protooncogene c-kit in peripheral blood mononuclear cells of patients who have mastocytosis with an associated hematologic disorder. Proc Natl Acad Sci USA 1995;92: 10560-10564.

17. Longley BJ, Tyrrell L, Lu S-Z, et al. Somatic c-kit activating mutation in urticaria pigmentosa and aggressive mastocytosis: establishment of clonality in a human mast cell neoplasm. Nat Genet 1996;12:312-314.

18. Tian Q, Frierson Jr HF, Krystal GW, et al. Activating c-kit gene mutations in human germ cell tumors. Am J Pathol 1999;154:1643-1647.

19. Went PT, Dirnhofer S, Bundi M, et al. Prevalence of KIT expression in human tumors. J Clin Oncol 2004;22:4514-4520.

20. Curtin JA, Busam K, Pinkel D, et al. Somatic activation of KIT in distinct subtypes of melanoma. J Cin Oncol 2006;24:4340-4346.

21. Lasota J, Wozniak A, Sarlomo-Rikala M, et al. Mutaions in exons 9 and 13 of KIT gene are rare events in gastrointestinal stromal tumors. Am J Pathol 2000;157:1091-1095.

22. Hirota S, Nishida T, Isozaki K, et al. Gain-of-function mutation at the extracellular domain of KIT in gastrointestinal stromal tumours. J Pathol 2001;193:505-510.

23. Kinoshita K, Isozaki K, Hirota S, et al. C-kit gene mutation at exon 17 or 13 is very rare in sporadic gastrointestinal stromal tumors. J Gastroenterol Hepatol 2003;18:147-151.

24. Demetri GD, von Mehren M, Blanke CD, et al. Efficacy and safety of imatinib mesylate in advanced gastrointestinal stromal tumors. N Engl J Med 2002;347:472-480.

25. Chen $\mathrm{H}$, Isozaki $\mathrm{K}$, Kinoshita $\mathrm{K}$, et al. imatinib inhibits various types of activating mutant KIT found in gastrointestinal stromal tumors. Int J Cancer 2003;105:130-135. 
26. Heinrich $\mathrm{MC}$, Corless $\mathrm{CL}$, Demetri $\mathrm{GD}$, et al. Kinase mutations and imatinib response in patients with metastatic gastrointestinal stromal tumor. J Clin Oncol 2003;21:4342-4349.

27. Wakai T, Kanda T, Hirota S, et al. Late resistance to imatinib therapy associated with a second KIT mutation in metastatic gastrointestinal stromal tumour. Br J Cancer 2004;90:2059-2061.

28. Nishida T, Kanda T, Nishitani A, et al. Secondary mutations in the kinase domain of the KIT gene are predominant in imatinibresistant gastrointestinal stromal tumor. Cancer Sci 2008;99: 799-804.

29. Heinrich MC, Maki RG, Corless CL, et al. Primary and secondary kinase genotypes correlate with the biological and clinical activity of sunitinib in imatinib-resistant gastrointestinal stromal tumor. J Clin Oncol 2008:26:5352-5359.

30. Nishida $T$, Hirota $S$, Taniguchi $M$, et al. Familial gastrointestinal stromal tumours with germline mutation of the KIT gene. Nat Genet 1998;19: 323-324.

31. Hirota S, Okazaki T, Kitamura Y, et al. Cause of familial and multiple gastrointestinal autonomic nerve tumors with hyperplasia of interstitial cells of Cajal is germline mutation of the c-kit gene. Am J Surg Pathol 2000;24:326-327.

32. Isozaki K, Terris B, Belghiti J, et al. Germline-activating mutation in the kinase domain of KIT gene in familial gastrointestinal stromal tumors. Am J Pathol 2000;157:1581-1585.

33. Maeyama $\mathrm{H}$, Hidaka $\mathrm{E}$, Ota $\mathrm{H}$, et al. Familial gastrointestinal stromal tumor with hyperpigmentation: association with a germline mutation of the c-kit gene. Gastroenterology 2001;120:210-215.

34. Beghini A, Tibiletti MG, Roversi G, et al. Germline mutation in the juxtamembrane domain of the kit gene in a family with gastrointestinal stromal tumors and urticaria pigmentosa. Cancer 2001; 92:657-662.

35. Hirota S, Nishida T, Isozaki K, et al. Familial gastrointestinal stromal tumors associated with dysphagia and novel type germline mutation of KIT gene. Gastroenterology 2002;122:1493-1499.

36. Robson ME, Glogowski E, Sommer G, et al. Pleomorphic characteristics of a germ-line KIT mutation in a large kindred with gastrointestinal stromal tumors, hyperpigmentation, and dysphagia. Clin Cancer Pathol 2004;10:1250-1254.

37. Carballo M, Aguilar F, Pol MA, et al. Novel c-KIT germline mutation in a family with gastrointestinal stromal tumors and cutaneous hyperpigmentation. Am J Med Genet A 2005;132:361-364.

38. Li FP, Fletcher JA, Heinrich MC, et al. Familial gastrointestinal stroma tumor syndrome: phenotype and molecular features in a kindred. J Clin Oncol 2005;23:2735-2743.

39. Kim HJ, Lim SJ, Park K, et al. Multiple gastrointestinal stromal tumors with a germline c-kit mutation. Pathol Int 2005;55:655-659.

40. Tarn C, Merkel E, Canutescu AA, et al. Analysis of KIT mutations in sporadic and familial gastrointestinal stromal tumors: therapeutic implications through protein modeling. Clin Cancer Res 2005;11: 3668-3677

41. Hartmann $\mathrm{K}$, Wardelmann $\mathrm{E}, \mathrm{Ma} \mathrm{Y}$, et al. Novel germline mutation of KIT associated with familial gastrointestinal stromal tumors and mastocytosis. Gastroenterology 2005;129:1042-1046.

42. O'Riain C, Corless CL, Heinrich $M C$, et al. Gastrointestinal stromal tumors: insights from a new familial GIST kindred with unusual genetic and pathologic features. Am J Surg Pathol 2005;29:1680-1683.

43. Lasota J, Miettinen M. A new familial GIST identified. Am J Surg Pathol 2006:30:1342.

44. Kang DY, Park CK, Choi JS, et al. Multiple gastrointestinal stromal tumors: clinicopathologic and genetic analysis of 12 patients. Am J Surg Pathol 2007;31:224-232.

45. Graham J, Debiec-Rychter $\mathrm{M}$, Corless $\mathrm{CL}$, et al. Imatinib in the management of multiple gastrointestinal stromal tumors associated with a germline KIT K642E mutation. Arch Pathol Lab Med 2007;131: 1393-1396.

46. Wozniak $A$, Rutkowski $P$, Sciot $R$, et al. Rectal gastrointestinal stromal tumors associated with a novel germline KIT mutation. Int J Cancer 2008;122:2160-2164.

47. Thalheimer A, Schlemmer M, Bueter $M$, et al. Familial gastrointestinal stromal tumors caused by the novel KIT exon 17 germline mutation N822Y. Am J Surg Pathol 2008;32:1560-1565.

48. Vilain RE, Dudding T, Braye SG, et al. Can a familial gastrointestinal tumour syndrome be allelic with Waardenburg syndrome? Clin Genet 2011;79:554-560.

49. Kuroda N, Tanida N, Hirota $\mathrm{S}$, et al. Familial gastrointestinal stroma tumor with germ line mutation of the juxtamembrane domain of the KIT gene observed in relatively young women. Ann Diag Pathol 2011;15:358-361.

50. Kinoshita K, Hirota S, Isozaki K, et al. Absence of c-kit gene mutations in gastrointestinal stromal tumours of neurofibromatosis type I patients. J Pathol 2004;202:80-85.

51. Kinoshita K, Hirota S, Isozaki K, et al. Characterization of tyrosine kinase I domain c-kit gene mutation Asn655Lys newly found in primary jejunal gastrointestinal stromal tumor. Am J Gastroenterol 2007;102: 1134-1136.

52. Nocka K, Tan JC, Chiu E, et al. Molecular bases of dominant negative and loss of function mutation at the murine c-kit/white spotting locus: $W^{37}, W^{v}, W^{41}$ and W. EMBO J 1990;9:1805-1813.

53. Heinrich MC, Owzar K, Corless CL, et al. Correlation of kinase genotype and clinical outcome in the North American Intergroup Phase III Tria of imatinib mesylate for treatment of advanced gastrointestinal stromal tumor: CALGB 150105 Study by Cancer and Leukemia Group B and Southwest Oncology Group. J Clin Oncol 2008;26:5360-5367.

54. Nakagomi N, Hirota S. Juxtamembrane-type c-kit gene mutation found in aggressive systemic mastocytosis induces imatinib-resistant constitutive KIT activation. Lab Invest 2007;87:365-371. 